\title{
Application of Seismic Risk Analysis and Earthquake Simulation Methods to the Western Region in Saudi Arabia
}

\author{
S.A. Ashour and H.H. Abdel-Rahman \\ Department of Civil Engineering, Faculty of Engineering, \\ King Abdulaziz University, Jeddah, Saudi Arabia
}

\begin{abstract}
This paper presents a series of applications of existing methods of seismic risk analysis and earthquake simulation to four major cities in the Western Region of Saudi Arabia.

Seismic risk maps available in literature, in the form of isointensity and isoacceleration graphs for the region. are first used to obtain design spectra for the four cities of Jizan, Jeddah, Makkah and Yanbu. Earthquake generation procedures are then applied to obtain the time history for ground acceleration, velocity and displacement.

It is believed that the artificial earthquakes generated in this work reasonably reflect the geological and seismic nature of the region and due to the complete lack of any recorded accelerograms, these artificial earthquakes could be of great value for the detailed analysis and design of earthquakeresistant structures in the region.
\end{abstract}

\section{Introduction}

Because of its geographical location, overlooking the Red Sea as shown in Fig. 1, the Western Region of Saudi Arabia is considered to be a moderately active seismic zone. Seismic events in the region that have been reported in literature include a significant earthquake, with a magnitude of 6.25 , that occurred in 1941 at about $30 \mathrm{~km}$ to the east of Jizan city ${ }^{[1]}$. Seismic events also include a sequence of earthquakes which occurred in 1967 along the Red Sea rift system at a distance of about $150 \mathrm{~km}$ to the south west of Jeddah ${ }^{[2]}$. Recently, El-Isa et al. ${ }^{[3]}$ reported that about 500 local earthquakes with magnitudes less than 4.85, occurred in the Gulf of Aqaba area during the period from January 21 to April 20, 1983. 


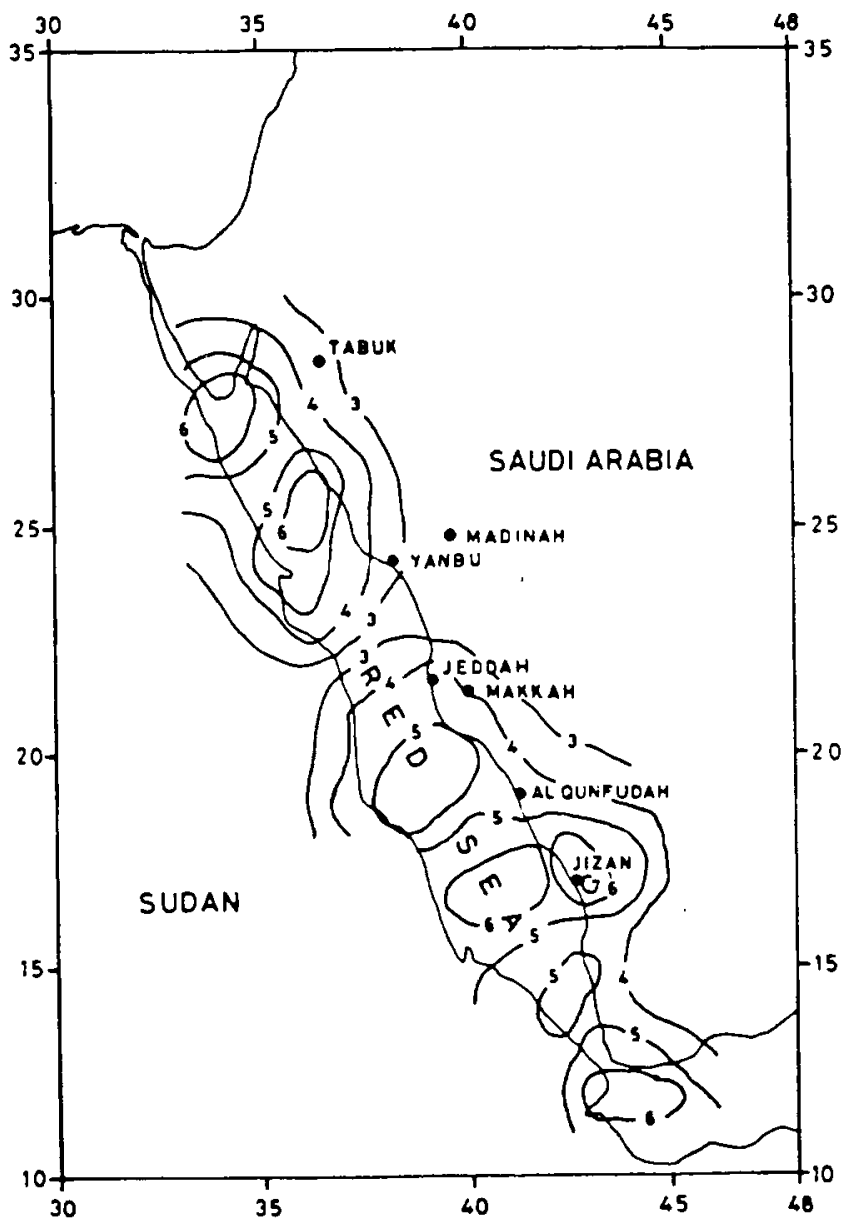

FIG. 1. Isointensity map, return period $=100$ year ${ }^{17]}$

Merghelani ${ }^{[4]}$ has also reported that a high level of microearthquake activity was detected near the border of the Red Sea and near the transition from oceanic to continental crust.

In seismic design, the design response spectra constitute the traditional means of specifying ground motion ${ }^{[5]}$. However, those design spectra, in some cases and especially for structures of high importance, provide less reliable results and time history analysis is needed.

The limitation and pausity of recorded accelerograms, together with the need to use time history dynamic analysis have motivated the development of earthquake simulation capabilities. The simulation should be based on realistic models that indeed reflect the general characteristics of the location in terms of seismic as well as geographical and geological characteristics. 
It is the main objective of this work to use an existing stochastic model ${ }^{[6-8]}$ and seismic risk maps ${ }^{|6|}$ to generate artificial ground acceleration time histories for the Western Region of Saudi Arabia. It is important to mention here that no real earthquake records; neither in terms of recorded time-histories nor peak ground accelerations have been available for the region.

In the next section the previous work on the seismicity of the Western Region of Saudi Arabia is briefly discussed. This is followed by a brief description of some available methods for generating artificial ground acceleration time histories based on available design spectra. The application of these methods on four major cities in the Western Region of Saudi Arabia and the resulting data are then discussed. Finally the main conclusions of this work are reported.

\section{Previous Work on Seismicity in Saudi Arabia}

Since the earthquake simulation applications presented in this paper based on the intensity maps prepared by $\mathrm{Ali}^{[6-7]}$ in a previous study; it is reasonable to define the basic concepts and to briefly state the specific relationships used for the intensity calculations. This section is devoted for this purpose.

\subsection{Magnitude-Frequency Relationship}

In the study made by $\mathrm{Alj}^{|6-7|}$, the recorded data of 192 seismic events were sorted and assigned to fourteen various sources. The magnitude-frequency relationship for each source was then obtained by linear regression using the familiar Richter's law :

$$
\log N=a-b M
$$

where $N$ is the number of occurrence per unit time greater than the magnitude $M$. The unit time was taken as 80 years $^{|f|}$. The range of $M$ magnitudes used in Eq. (1) was 5 to 7.33

\subsection{Attenuation Model}

Several attenuation models based on empirical formulation and observation have been proposed in literature ${ }^{[8-13]}$. However, $\mathrm{Al}^{[6]}$ adopted the following attenuation model proposed by Cornell ${ }^{[8]}$ :

$$
I(M, R)=C_{1}+C_{2} m-C_{3} \ln \left(r+r_{n}\right)
$$

where the values of $C_{1}, C_{2}, C_{3}$ and $r_{0}$ are set to be :

$$
\begin{aligned}
& C_{1}=8 \\
& C_{2}=1.5 \\
& C_{3}=2.5 \\
& r_{0}=20
\end{aligned}
$$


In Eq. (2), $I$ is the mean value of the distribution of modified Mercalli intensity, $r$ is the epicentral distance in kilometers, and $m$ is the earthquake size in surface wave magnitude.

The adaption of Cornell's attenuation model, which has been developed for firm ground in Southern California, in Ali's study may be questionable. However, due to the apparent difficulty of the total lack of real records, attenuation models that relate peak ground acceleration or velocity to the magnitude and distance ${ }^{[15-16]}$ could not be established. It seems that Ali ${ }^{|6|}$ has adapted Cornell's model following a similar study made by Teikari et al. ${ }^{[17]}$ for northern Iraq, a nearby region, in which a similar attenuation model was used.

\subsection{Probabilistic ModeI}

The probabilistic model used by $\mathrm{Ali}^{|6|}$ was based on the total probability :

$$
P[I>i]=\iint P\left[I>i|m, r| f_{M}(m) f_{R}(r) d m d r\right.
$$

where $P$ indicates probability, $I$ is the event whose probability is sought, and $M$ and $R$ are continuous independent random variables which influence $l$. For more details the interested reader is referred to reference ${ }^{|6|}$.

Once the risk associated with an intensity level $i$ at a site has been calculated for the occurrence of one earthquake of arbitrary magnitude and location in a source, the annual expected number of events from that source which cause intensity $i$ or greater, is obtained by multiplying the single event risk by the expected number of events during one year. The total expected number of events causing intensity $I>i$ at the site is obtained by summing the expected number from each source. Risks are then calculated assuming that earthquakes occur as Poisson"s arrivals, that is :

$$
\text { Risk }=1-\exp (- \text { total expected number })
$$

Ali $^{\mid[j]}$ used a computer program developed by McGuire ${ }^{[18]}$ for his seismic risk analysis.

The results were presented in the form of isointensity maps that correspond to some selected return periods and represent 10 percent chance of exceeding. In the present study, the seismic risk map that corresponds to a return period of 100 year and future exposure time of 10 years. Fig. 1, is chosen as the basis for the application of earthquake simulation. From this map, the intensities at the four cities of Jizan, Jeddah, Makkah and Yanbu, are found to be $6.95,4.33,3.7$ and 3.25 respectively, with 0.01 risk per year.

\subsection{Isoacceleration Maps}

Since isointensity maps have limited direct use in seismic design; design accelerations have to be determined based on the corresponding intensity levels. Ali ${ }^{[7]}$ used the method proposed by Krinitzsky and Chang ${ }^{[19]}$ to establish isoacceleration maps corresponding to the selected return periods. The justification given by $\mathrm{Ali}^{\left[{ }^{[7]}\right.}$ for his choice of Krinitzsky and Chang's method is that most of the epicenters of reported 
earthquakes in the Western Region of Saudi Arabia exist in the Red Sea ${ }^{[2-4,6]}$ and hence it seems appropriate to use the far field curves. Since there is a wide scatter in the data used to establish these curves, Ali selected the $100 \%$ curve for the determination of accelerations based on safety and conservatism criteria. Figure 2 shows the isoacceleration map for a return period of 100 years and $10 \%$ chance of exceeding ${ }^{77]}$. The peak ground acceleration for Jizan is $0.24 \mathrm{~g}$, for Jeddah is $0.09 \mathrm{~g}$ for Makkah is $0.05 \mathrm{~g}$, and for Yanbu is $0.03 \mathrm{~g}$.

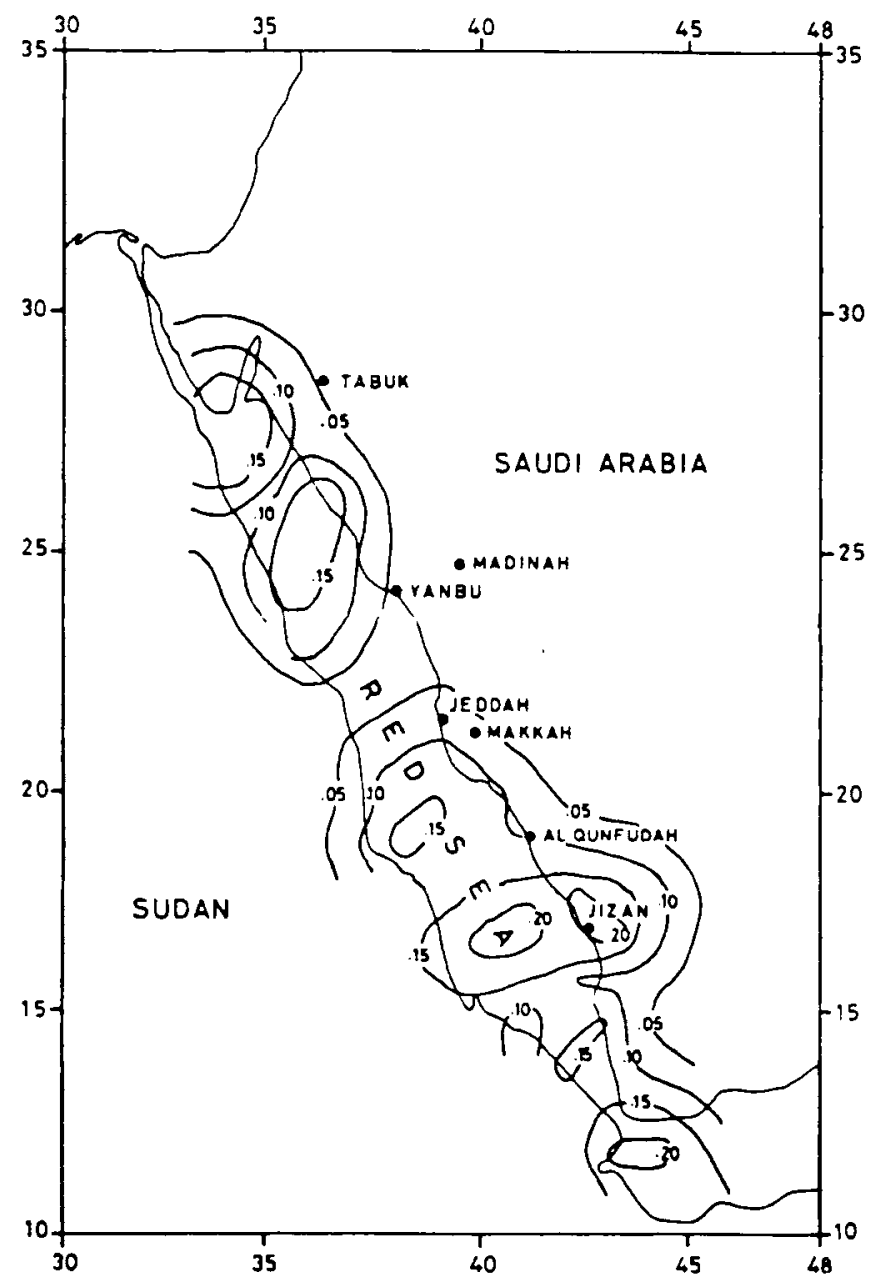

FIG. 2. Isoacceleration map, return period $=100$ year $^{|7|}$.

\section{Earthquake Simulation Methods}

There are several methodologies proposed in literature for earthquake simulation $^{[5,20-24]}$. However for the specific purpose of this study the method developed by 
Gasparini and Vanmarcke $\mathrm{e}^{[20]}$ is adopted.

\subsection{Design Response Spectra}

The Newmark method ${ }^{[25-27]}$, for the construction of response spectra, is employed in the present study to get the design response spectra for the four cities under consideration using the peak ground accelerations obtained before. It should be mentioned here that Newmark's procedure involves the scaling of standard spectra shapes, obtained by normalyzing the response spectra of recorded ground motions, to the design values of the ground motion parameters. Hence the method assumes that motions of different intensities are similar in same respect. Despite this fact, it has been resorted to this method due to the complete lack of real records. Other methods such as that reported by McGuire ${ }^{[1.5]}$ can be only used if recorded data is available. The calculated design response spectra are shown in Fig. 7 (a-d) as dashed lines.

\subsection{Review of the Generation Procedure}

A brief description of the generation method developed by Gasparini and Vanmarcke is now given, while more details can be obtained from reference ${ }^{\mid 20]}$. The method is based on the fact that any periodic function can be expanded into a series of sinusoidal waves.

$$
\ddot{z}(t)=\sum_{n} A_{n} \sin \left(\omega_{n} t+\theta_{n}\right)
$$

in which $\ddot{z}$ is the base acceleration, $A_{n}$ is the amplitude, $\omega_{n}$ and $\theta_{n}$ are the frequency and phase angle of the $n$th contributing sinusoid respectively. The algorithm uses random number generator to produce strings of phase angles with uniform likelihood in the range between 0 and $2 \pi$.

The amplitudes $A_{n}$ are reflected to the (one-sided) spectral density function $G\left(\omega_{n}\right)$ in the following way :

$$
G\left(\omega_{n}\right)=\frac{A_{n}}{2}
$$

Since the total power may be expressed as :

$$
\Sigma A_{n}^{2} / 2=\Sigma G\left(\omega_{n}\right) \cdot \Delta \omega
$$

then, for large number of sinusoids, the total power will become the area under the continuous curve $G(\omega)$, such as :

$$
\Sigma A_{n}^{2} / 2=\int_{o}^{\infty} G(\omega) d \omega
$$

The method establishes a relationship between the response spectrum $(S V)$ and the spectral-density function $G(\omega)$ of ground motion at a site. The relationship is not unique, though; it depends on the chosen strong motion duration, on the exceedance probability level assigned, and on the damping level involved ${ }^{[20]}$. 
The power of motion calculated by Eq. (5) does not vary with time. To simulate the transient nature of real earthquakes, the steady state motions are multiplied by a deterministic function $I(t)$. There are several patterns in which the deterministic envelope $I(t)$ can be expressed. These involve trapezoidal, exponential and compound shapes $^{[20)}$.

The artificial motion $\ddot{z}(t)$ then becomes :

$$
\ddot{z}(t)=I(t) \sum_{n} A_{n} \sin \left(\omega_{n} t+\theta_{n}\right)
$$

The resulting motion is stationary in frequency content with a peak acceleration close to the target peak acceleration. The response spectra corresponding to the motion are then calculated using the method reported by Nigam and Jennings ${ }^{[28]}$ which is based on exact solution of the differential equation of motion. To smooth the calculated spectra and to improve the match, iteration is implemented in the generation procedure. This is done by modifying the spectral density function as follows :

$$
G(\omega)_{i+1}=G(\omega)_{i}\left[S V(\omega) / S V_{t i}(\omega)\right]^{2}
$$

where $S V(\omega)$ is the calculated velocity spectra and $S V_{t i}(\omega)$ is the target velocity spectra for the control frequency in the $i$ th cycle. The procedure may not converge at all control frequencies, because the response at a control frequency is dependent on the spectral density function value for that frequency as well as values at other frequencies close to the frequency of interest.

\subsection{Base Line Correction}

There are many significant contributions in literature to the general problem of base-line correction and double integration of digitized accelerograms ${ }^{|29-31|}$. The parabolic base line correction ${ }^{|29|}$ has been used for the present study. The correction considers the duration of motion in calculating the constant coefficients in the parabolic equation ${ }^{[29]}$ :

$$
\ddot{z}_{2}(t)=\ddot{z}_{1}(t)+a_{1}+a_{2} t+a_{3} t^{2}
$$

where $\ddot{z}_{2}(t)$ is the corrected accelerogram and $\ddot{z}_{1}(t)$ is the ground acceleration before correction.

\subsection{Strong Motion Duration}

Due to lack of recorded accelerograms for the region under consideration, the duration of the strong phase of the simulated motion could not be established in a rational manner. However, it should be as short as possible if it is not specified from the seismo-tectonic conditions governing site seismicity ${ }^{[5]}$, bearing in mind that it should at least allow the steady state structural response to be achieved. A minimum strong motion duration of 6 seconds (coupled with a built-up duration of 4 seconds) is recommended for nuclear power plant ${ }^{\mid 32]}$. In general, the duration tends to decrease with increasing intensity level and increases with the increase of the epicentral distance for a specified intensity level ${ }^{[31]}$. The total duration of the simulated motions in the present study has been established based on the following formula proposed by 
Esteva and Rosenblueth ${ }^{|33|}$ :

$$
T=0.02 e^{0.74 M}+0.3 R
$$

where $M$ is the earthquake magnitude and $R$ is the epicentral distance. The modulation enveloped of the simulated motions may be expressed as :

$$
\begin{aligned}
& 56.25 \frac{l}{T} \\
& 0 \leq t \leq \frac{2}{15} T \\
& I(t)=\quad 1.0 \\
& \frac{2}{15} T \leq t \leq \frac{T}{2} \\
& \exp \left[-2.976\left(\frac{t}{T}-\frac{1}{2}\right)\right] \frac{T}{2} \leq t \leq T
\end{aligned}
$$

such envelope has been widely used for probabilistic response of structures due to artificial earthquakes ${ }^{[34-35]}$.

\section{Applications to the Western Region in Saudi Arabia}

\subsection{Simulated Motion Parameters}

The application of earthquake simulation procedures on the four major cities of Jizan, Jeddah, Makkah and Yanbu in the Western Region of Saudi Arabia starts by defining a set of parameters on which the process is based. These parameters are given in Table 1. The epicentral distances are established based on the assumption that epicenters are located along the axial trough of the Red Sea ${ }^{|6|}$. The correspond-

\begin{tabular}{|c|c|c|c|c|}
\hline Motion & Jizan & Jeddah & Makkah & Yanbu \\
\hline Intensity (mm) & 6.95 & 4.33 & 3.7 & 3.25 \\
\hline Epicentral distance $(R \mathrm{~km})$ & 175 & 110 & 155 & 125 \\
\hline Magnitude $(M)$ & 8.08 & 5.67 & 5.74 & 5.13 \\
\hline Total duration ( $T \mathrm{sec}$ ) & 60 & 35 & 50 & 40 \\
\hline Cutoff period (sec) & 7 & 7 & 7 & 7 \\
\hline
\end{tabular}
ing magnitudes are established from the attenuation relation given by $\mathrm{Eq}$. (2). The total duration for each case is determined by Eq. (12). The modulation time envelope described by Eq. (13) is used for each case with a total duration corresponding to that case.

TABLE 1. Input parameters of the simulated motions.

A rough estimation of the cutoff periods for the motions may be based on the response spectra of the filtered motion for short earthquakes and on the frequency content of the ground velocity and displacement for large earthquakes ${ }^{|20|}$. However, as mentioned before, since no recorded events are available, the proposed cutoff 
periods are chosen arbitrarily, but expected to give acceptable results.

\subsection{Time Histories and Response Spectra}

The calculated time histories of ground acceleration, velocity, and displacement are shown in Fig. 3-6 for Jizan, Jeddah, Makkah and Yanbu respectively. The velocity and displacement time histories have been obtained by integrating and simulated acceleration time history after applying the base line correction. The maximum values of these ground motions are given in Table 2. The frequency content is reflected on the simulated motions since all the design spectra have wide frequency range.

TABLE 2. Output parameters of the simulated motions.

\begin{tabular}{|l|r|r|r|r|}
\hline \multicolumn{1}{|c|}{ Motion } & Jizan & Jeddah & Makkah & Yanbu \\
Output \\
parameter
\end{tabular}

The corresponding response spectra for 2, 5 and $10 \%$ damping are shown in Fig. 7. The calculated spectra have been obtained for 200 values of natural periods. It can be noticed that for almost all the spectra, the agreement between the design target spectra ( $5 \%$ damping) and the calculated spectra is quite reasonable for all ranges of period values with excellent agreement for short period range of 0.1 to 3.5 second. The effect of the cutoff period is clearly reflected on the simulated motions where rapid decrease in the response spectra of all motions is noticeable for periods greater than seven seconds.

Table 2 gives also the spectral intensity $(S I)$, defined as :

$$
S I_{5 \%}=\int_{0.1}^{2.5} S V\left(5 \%, T_{n}\right) d T_{n}
$$

for all calculated spectra. Figure 8 shows the energy input per unit mass spectra of the simulated motions for $0,2,5$, and $10 \%$ fraction of critical damping.

The damage potential in terms of the mean-square integral which is defined as :

$$
D P=\int_{0}^{T} \ddot{z}^{2}(t) d t
$$

is a reasonable measure of the intensity of a ground motion ${ }^{[36]}$. The mean-square integral is shown in Fig. 9 for the generated motions. Applying the criteria of the strong motion duration as defined by Trifunac and Brady in references ${ }^{[36-37]}$; it is found from Fig. 9 that Jizan has a duration of 38.54 seconds and Jeddah has 22.3 seconds. From 
(O)
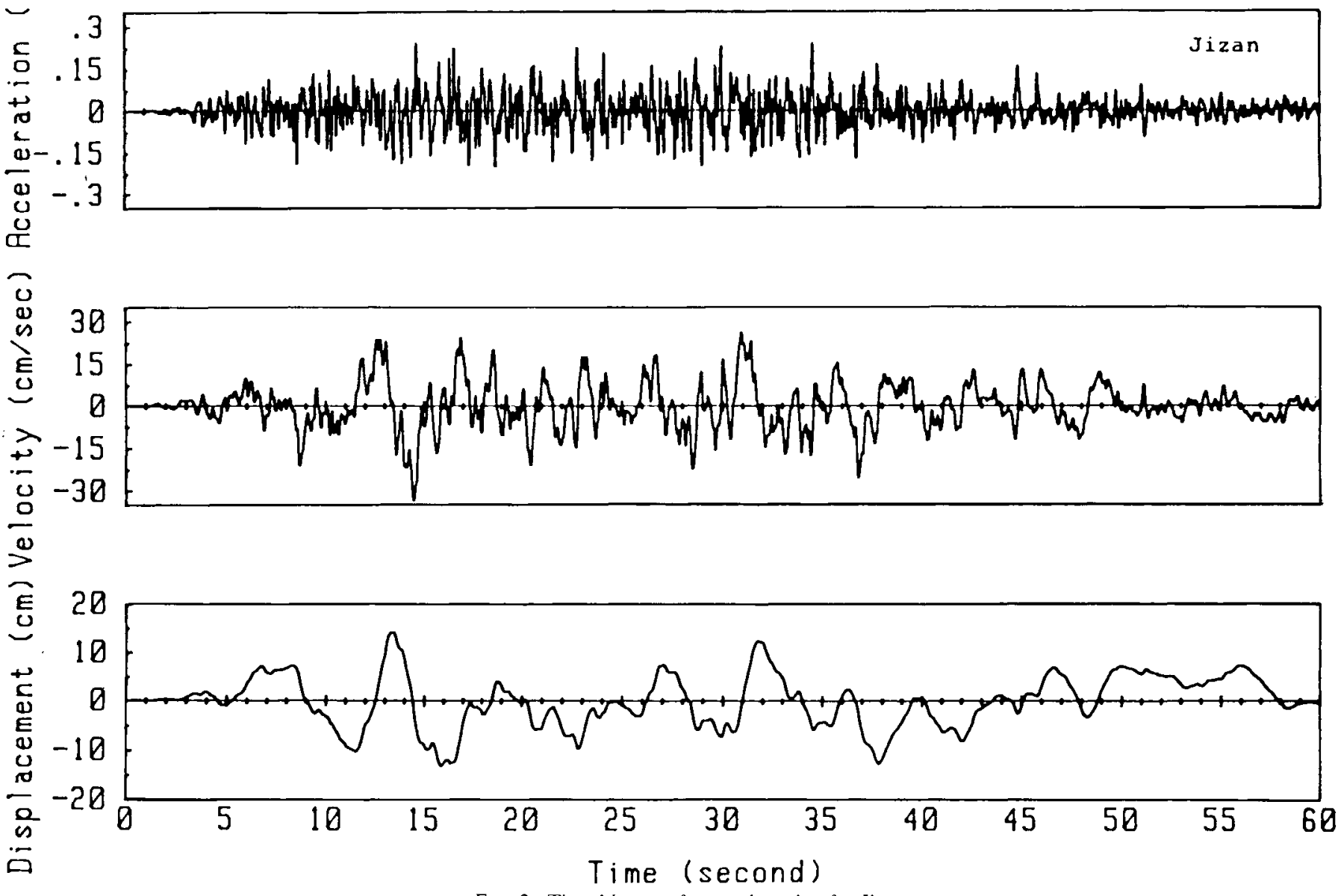


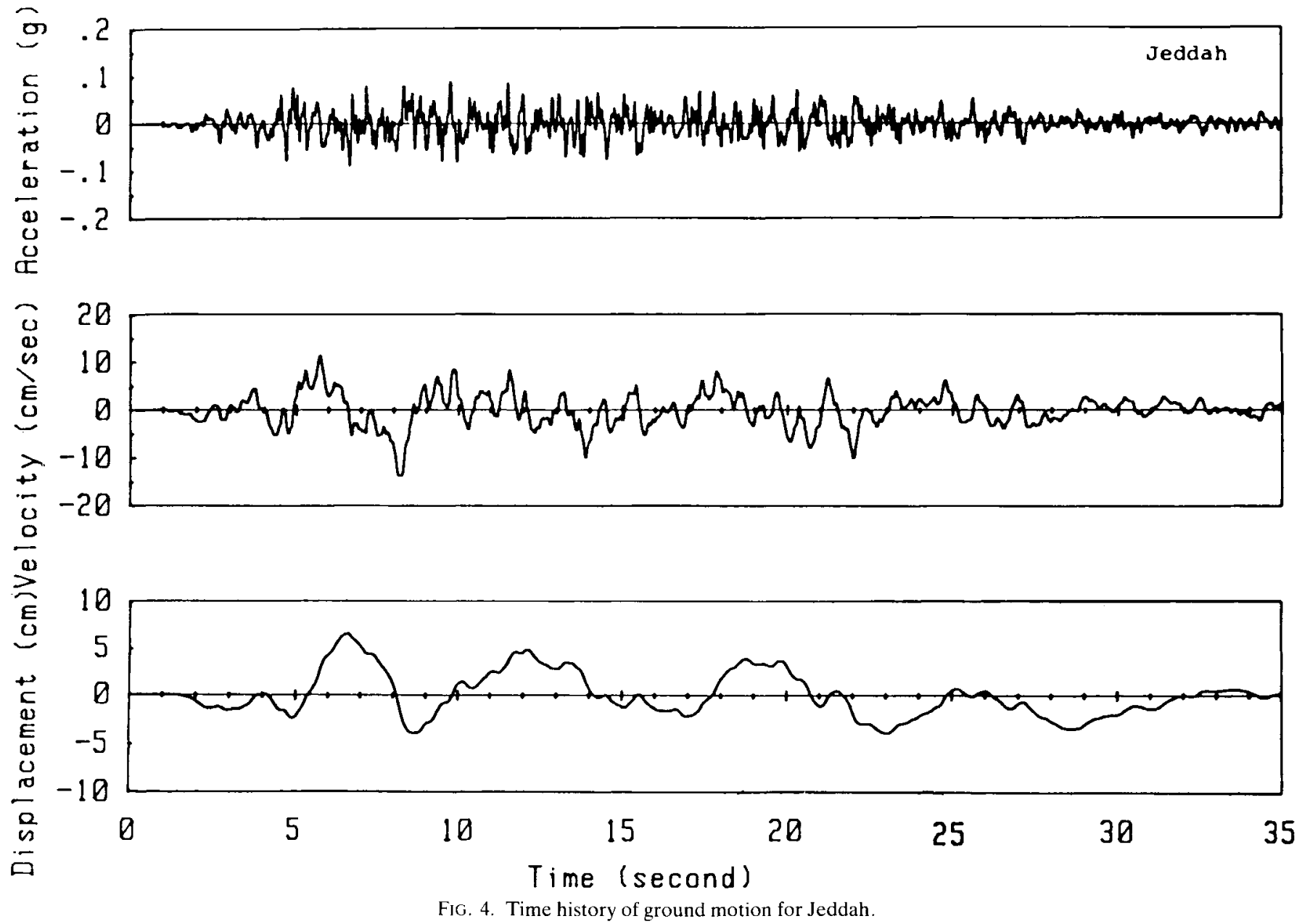



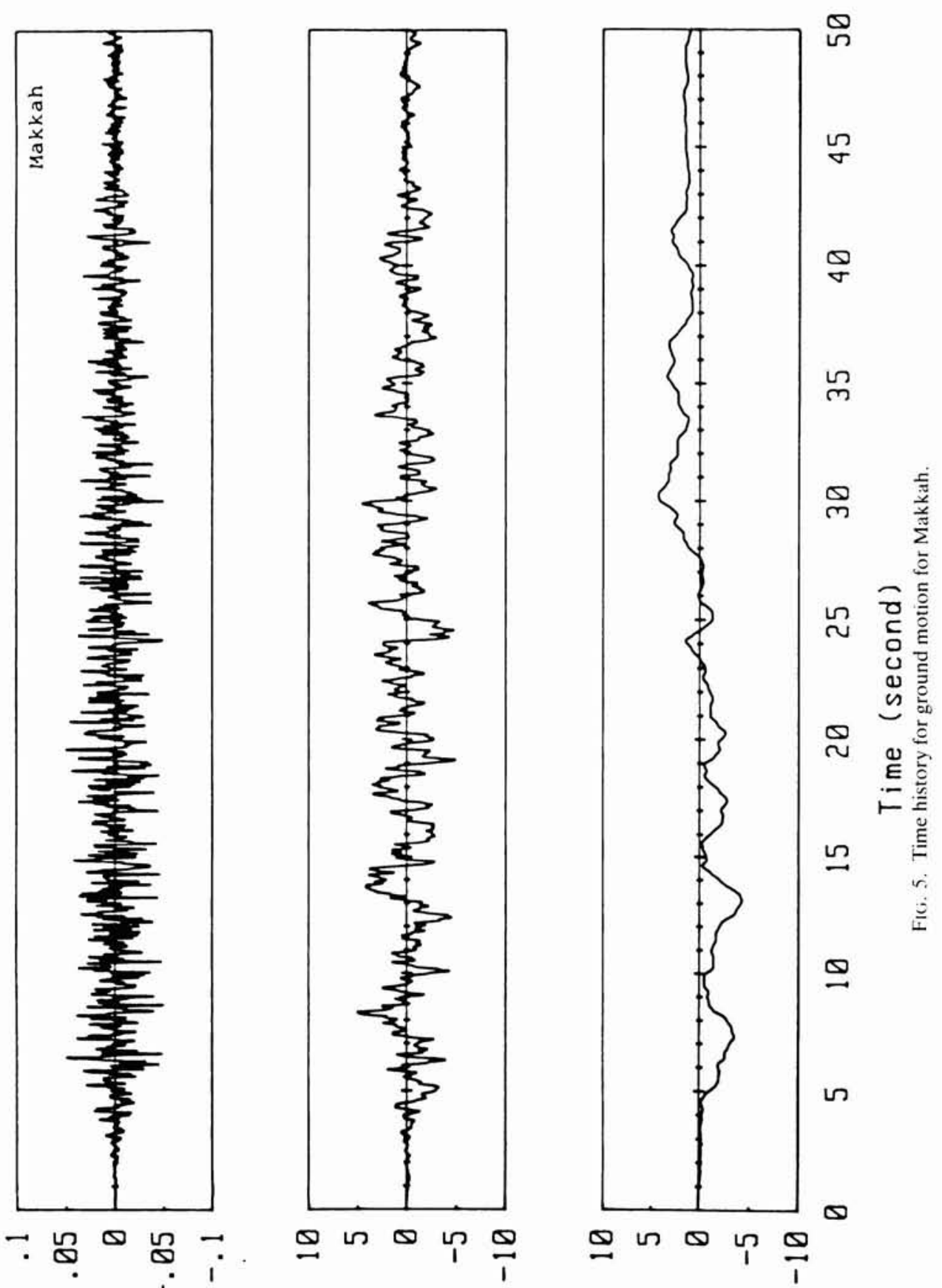

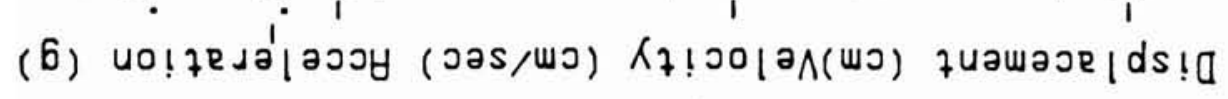



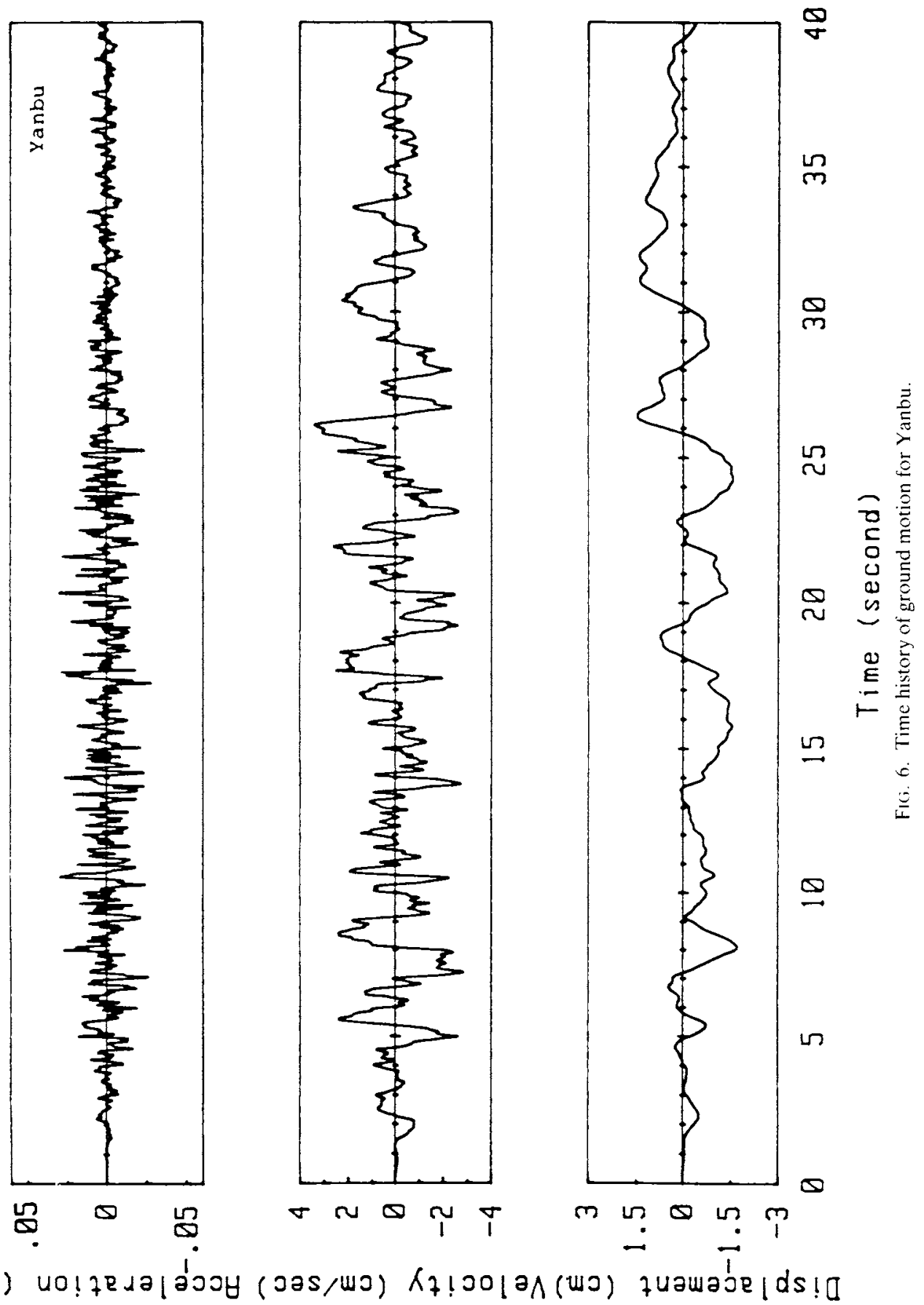

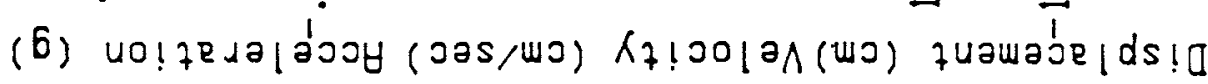



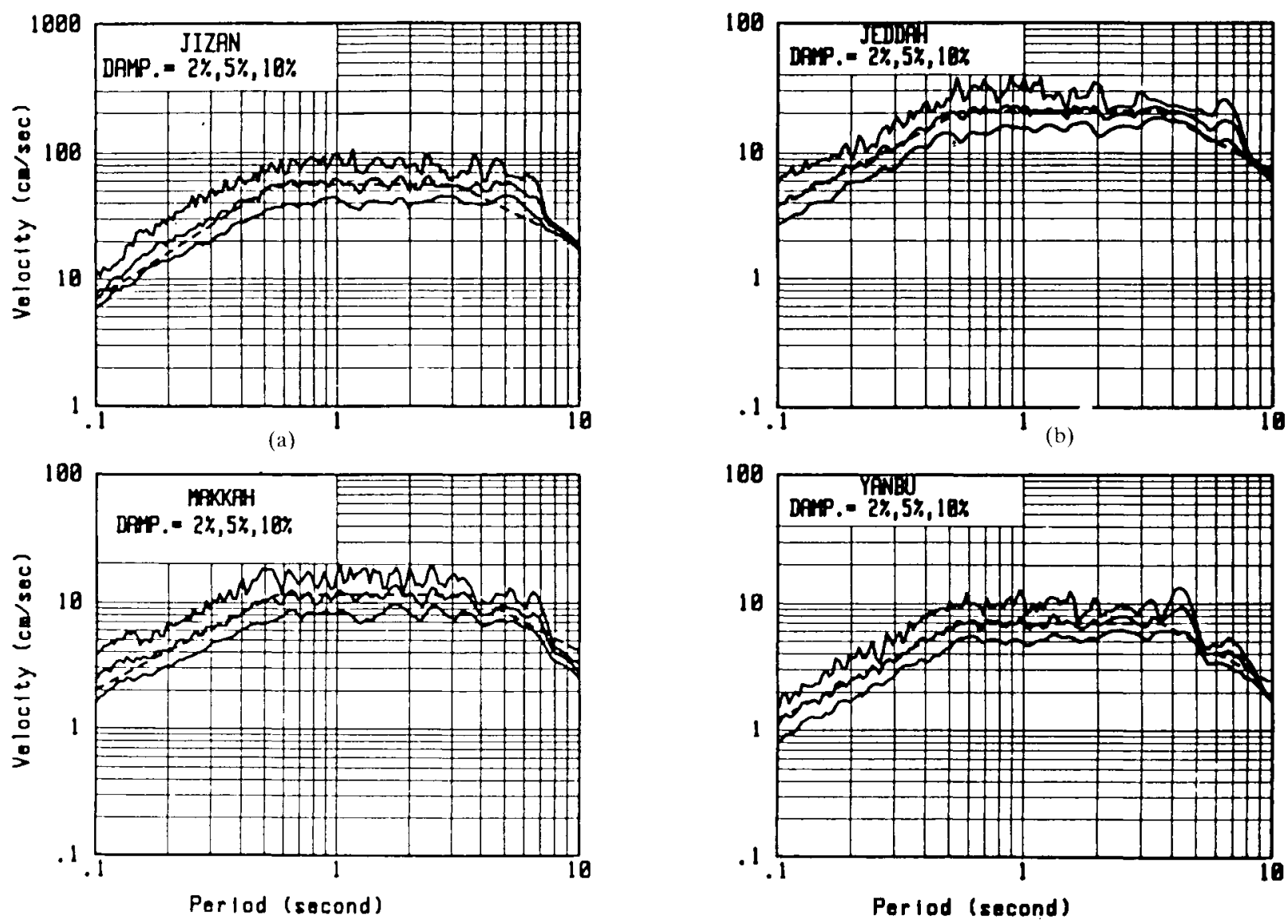

(c)

Fig. 7. Response spectra: (a) Jizan, (b) Jeddah, (c) Makkah, (d) Yanbu. 

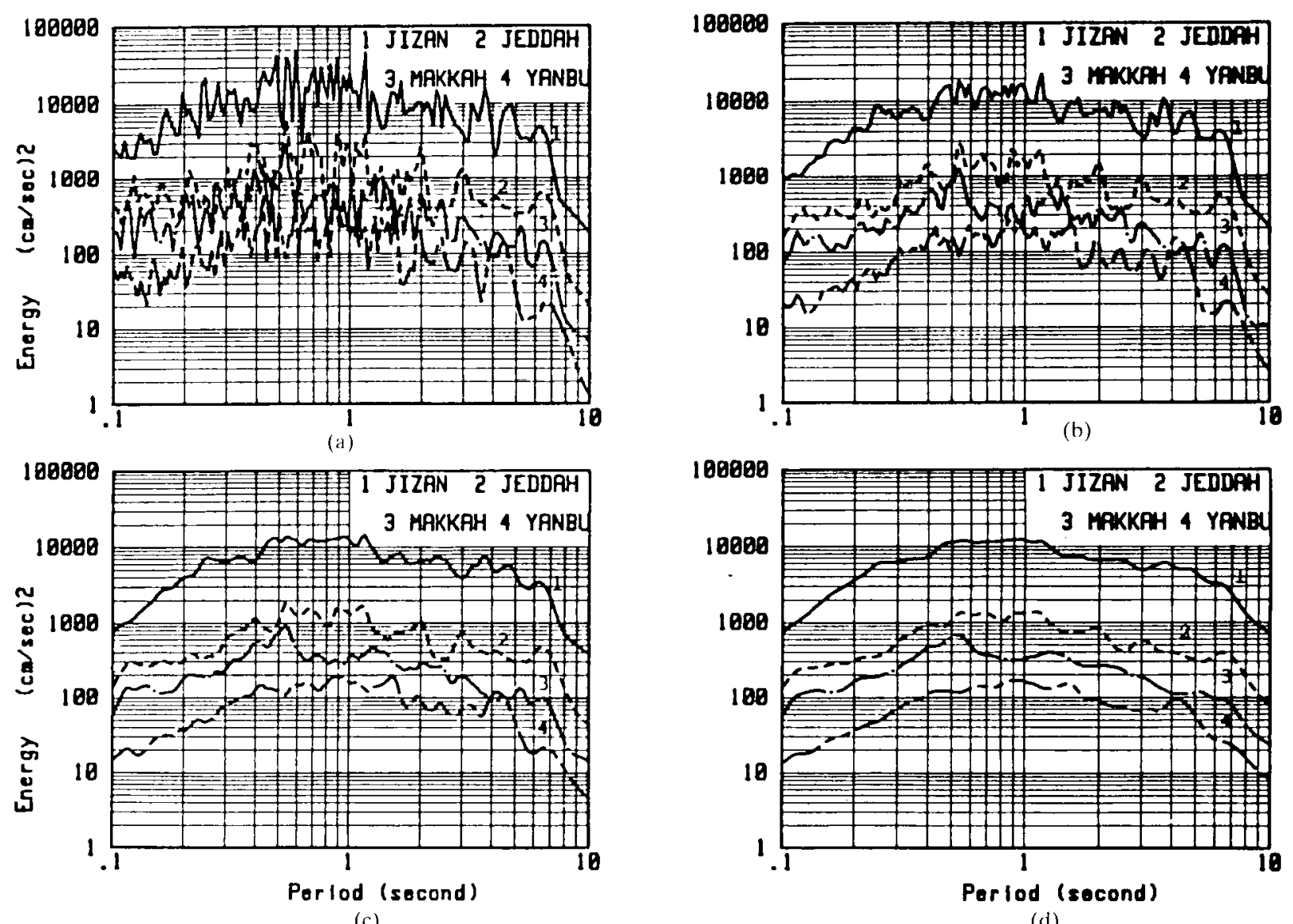

(c)

(d)

FIG. 8. Energy input per unit mass spectra: (a) $10 \%$ damping. (b) $2 \%$ damping. (c) $5 \%$ damping, (d) $10 \%$ damping. 

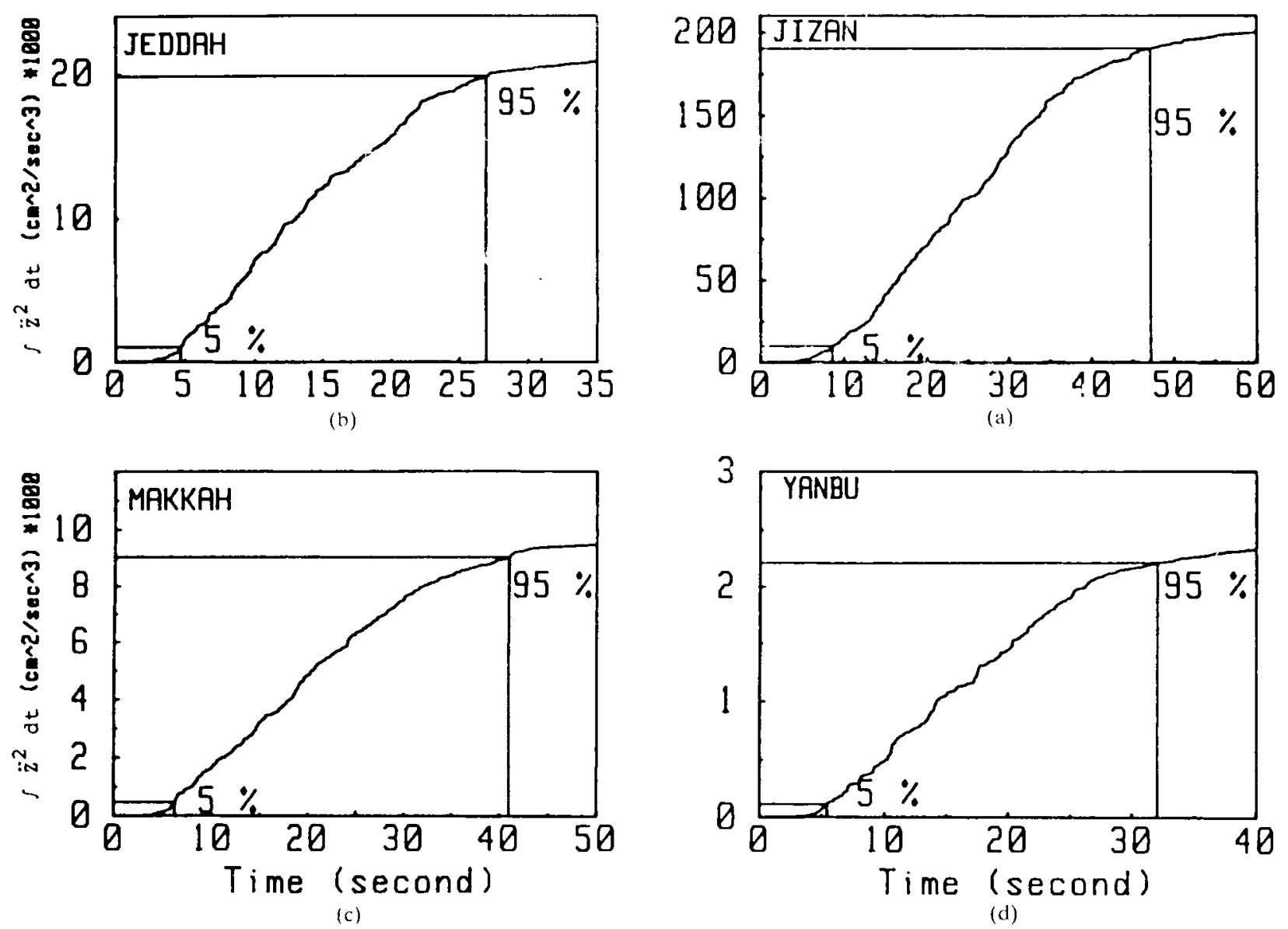

Flri. 9. Mean-square acceleration integral: a) Jizan, (b) Jeddah, (c) Makkah, (d) Yanbu. 
the same figure, the durations for Makkah and Yanbu are 34.7 and 26.6 seconds respectively.

Another parameter that characterizes strong ground motion is the root-meansquare (RMS) acceleration which is defined as ${ }^{[37]}$ :

$$
\mathrm{RMS}=\left[\frac{1}{T} \int_{0}^{T} \ddot{z}^{2}(t) d t\right]^{1 / 2}
$$

The cumulative RMS function (CRF) is a continuous representation of the RMS as a function of time. To determine the CRF, the RMS is calculated at every time increment of the acceleration record. The CRF provides a clear picture of the times at which pulses or groups of pulses of energy arrive ${ }^{[37]}$. Figure 10 shows the CRF for the simulated motions with the trend of real motions provides a reasonable representation of the simulated motions as an input for future seismic design.

The generated accelerograms enable a more reliable time history integration to be performed for the determination of seismic building response in the region. However, as pointed out by Vanmarcke ${ }^{|38|}$, "a design response spectrum is developed to cover different possible ground motions (e.g., caused by large distant earthquakes or close moderate earthquakes) each with its own frequency content and expected duration. The common practice of generating simulated motions for use in design based on a single spectral density function appears to be justified only if one earthquake source accounts for nearly all of the total site seismic risk, or if the local geology is principally responsible for shaping the frequency content of the ground motion. Otherwise, it is necessary to reexamine the data on seismicity and attenuation to determine the relative likelihood of occurrence of the various types of site ground motion and frequency content. These issues need considerable further study.

\section{Conclusion}

Applications of available procedures of transforming design ground acceleration and design spectra, obtained by seismic risk analysis, into time history accelerograms have been presented in this paper. This involves generating artificial earthquake reocords for the four major cities of Jizan, Jeddah, Makkah and Yanbu in the Western Region of Saudi Arabia with computed spectra that match certain prescribed target spectra with a specified damping. The target design spectra for each city has been calculated using the corresponding peak ground acceleration for the city, obtained from seismic risk maps available in literature for the region.

The artificial earthquakes obtained in this work reasonably reflect the geological and seismic nature of the Western Region in Saudi Arabia and provide better approach for the analysis and design of structures that are required to have reliable resistivity for seismic forces. 

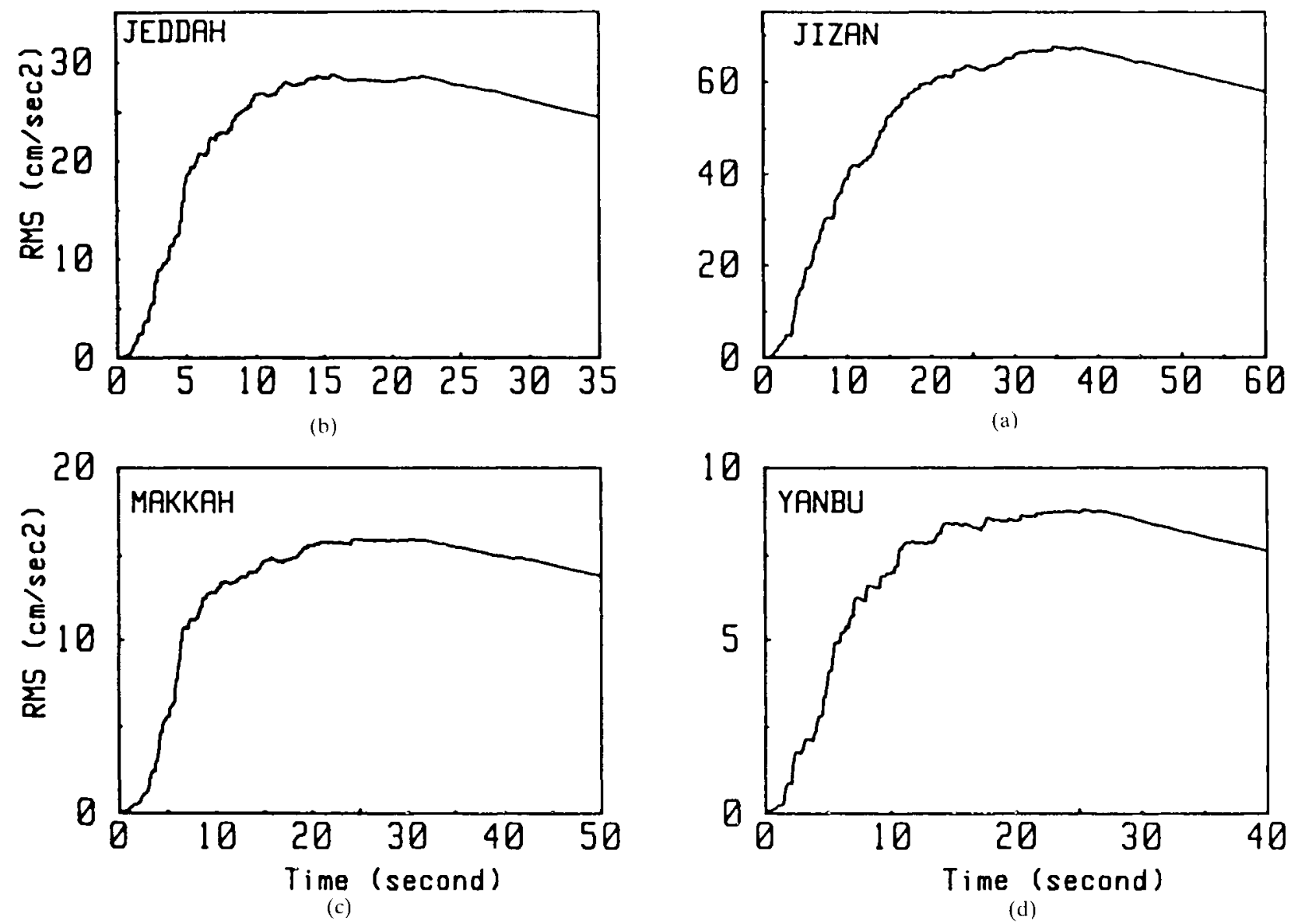

Fic. 10. Root-mean-square acceleration integral: a) Jizan, b) Jeddah, c) Makkah, d) Yanbu. 


\section{References}

[1] Gutenberg, B. and Richter, C., Seismicity of the Earth and Associated Phenomena, Hafner Publishing Co.. New York and London, p. 310 (1965).

[2] Barazangi, M., Evaluation of seismic risk along the western part of the Arabian Plate: Discussion and recommendations. Bulletin of Faculty of Earth Science, King Abdulaziz University, 4: 77-87 (1981).

[3] El-Isa, Z.H., Merghelani, H.M. and Bazzani, M.A., The Qulf of Aqaba earthquake sworn of 1983 January-April. Geophys. J.R. Abstr. Soc., 78: 711-722 (1984).

[4] Merghelani, H.M., Seismicity of the Tihamat-Asir Region, Kingdom of Saudi Arabia. U.S. Geological Survey Saudi Arabian Proj. Report. 25I, p. 20 (1979).

[5] Andre, P., The generation of spectrum compatible accelerograms for the design of nuclear power plants. Earthquake Engineering and Structural Dynamics, 12: $481-497$ (1984).

[6] Ali, S.A., Criteria and design of earthquake resistant structures in Western Saudi Arabia, Final Report, Project 02-108, Faculty of Engineering, King Abdulaziz University, Saudi Arabia (1983).

[7] Ali, S.A., Design of earthquake resistant structures in Western Saudi Arabia, Final Report, Project 04-315. College of Engineering, King Abdulaziz University, Saudi Arabia (1985).

[8] Cornell, C.A., Engineering seismic risk analysis, Bull. Seism. Soc. Am., 58: 1583-1606 (1968).

[9] Howell, B.F. and Schultz, T.R., Attenuation of modified mercalli intensity with distance from epicenter, Bull. Seism. Soc. Am., 63: 651-665 (1975).

[10] Espinosa, A.F., Attenuation of strong horizontal ground accelerations in the Western United States and their relation to $M_{L}$, Bull. Seism. Soc. Am., 72: 583-616 (1980).

[11] Nuttli, O.W. and Herrman, R.B., Ground motion of Mississippi valley earthquakes, Journal of Technical Topics in Civil Engineering, 110: 54-69 (1984).

[12] Gutenberg, B. and Richter, C.F., Earthquake magnitude intensity, energy, and acceleration. Bull. Seism. Soc. Am., 32: 163-191 (1942).

[13] Gutenberg, B. and Richter, C.F., Earthquake magnitude, intensity, energy, and acceleration, Bull. Seism. Soc. Am., 46: 105-145 (1956).

[14] Esteva, L. and Rosenblueth, E., Spectra of earthquakes at moderate and large distances, Soc. Mex. de Ing. Sismica, Mexico II, 1-18 (1964).

[15] McGuire, R.K., Seismic design spectra and mapping procedures using hazard analysis based directly on oscillator response. Earthquake Engineering and Structural Dynamics, 5: 211-234 (1977).

[16] Campell, K.W., Near source attenuation of peak horizontal acceleration. Bull. Seism. Sec. Am.. 71: 2039-2070 (1981).

[17] Teikari, P. et al., Seismic Activity and Hazard Assessment for Northern Iraq. University of Helsinki. Published by Imatran Voima Oy. Helsinki (1981).

[18] McGuire, R.K., Fortran computer program for seismic risk analysis, U.S. Deparment of Interior Geological Survey Open File Report 76-67 (1976).

[19] Krinitzsky, E.L. and Chang, F.K., State-of-art for Assessing Earthquake Hazards in the United States. Report 7. Specifying peak motions for design earthquakes, U.S. Waterways Experiment Station, No. S-73-1 (1977).

[20] Gasparini, D. and Vanmarcke, E.H. Simulated Earthquake Motions Compatible with Prescribed Response Spectra, Research Report R76-4. Department of Civil Engineering, M.I.T., January (1976).

[21] Jennings, P.C., Housner, G.W. and Tsi, N.C., Simulated earthquake motions. Earthquake Engineering Research Laboratory Report, California Institute of Technology, Pasadena, California, April (1968).

[22] Hadley, D.M. and Helmberger, D.V., Simulation of strong ground motions, Bull. Seism. Soc. Am., 70: $617-630$ (1980)

[23] Kameda, H. and Nojima, N., Simulation of risk-consistent earthquake motion, Earthquake Engineering and Structural Dynamics, 16: 1007-1019 (1988)

[24] Housner, G.W. and Jennings, P.C., Generation of artificial earthquakes, J. Eng. Mech. Div., ASCE, 90 (EM1): 113-150(1964). 
[25] Newmark, N.M. and Hall, W.J., Seismic design criteria for nuclear reactor facilities. Proc. 4th Wld Conf. Earthq. Engng, Santiago, Chile (1969)

[26] Newmark, N.M., Blume, J.A. and Kapur, K.K., Seismic design spectra for nuclear power plants. Journal of Power Division, ASCE. 99: 287-303 (1973).

[27] Newmark, N.M. and Hall, W.J., Procedures and Criteria for Earthquakes Resistant Design. Building Science Series 46, Building Practices for Disaster Mitigation, U.S. Department of Commerce. National Bureau of Standards (1973).

[28] Nigam, N.C. and Jennings, P.C., Digital Calculation of Response Spectra from Strong Motion Earthquake Records. Earthquake Engineering Research Laboratory Report. California Institute of Technology. Pasadena. California. June (1968).

[29] Berg, G.V. and Housner, G.W., Integrated velocity and displacement of strong earthquake ground motion. Bull. Seism. Soc. Am., 51(2): April: (1961).

[30] Trifunac, M.D., Low Frequency Digitization Errors and a New Method for Zero Base-line Correction of Strong-Motion Accelerograms, EERL 70-07 Earthquake Engineering Research Laboratory Report. California Institute of Technology. Pasadena. California. September (1970).

[31] Trifunac, M.D. and Lee, V., Routine Computer Processing of Strong-Motion Accelerograms, EERL 73-03 Earthquake Research Laboratory Report, California Institute of Technology. Pasadena. California. October (1973).

[32] Lin, C.W., Criteria for Generation of Spectra Consistant Time Histories, SMIRT-4. San Francisco. Paper K1/11 (1977).

[33] Esteva, L. and Rosenblueth, E., Espectros de temblores a distancias moderados y grandes. Bol. Soc. Mex. Ing. Seism., 2(1): 1-18 (1964).

[34] Jeong, G.D. and Iwan, W.D., The effect of earthquake duration on the damage of structures, Earthquake Engineering and Structural Dynamics, 16: 1201-1211 (1988).

[35] Saragoni, G.R. and Hort, G.C., Simulation of artificial earthquakes. Earthquake Engineering and Structural Dynamics, 2: 249-267 (1974).

[36] Trifunac, M.D. and Brady, A.G., A study on the duration of strong earthquake ground motion. Bull. Seism. Soc. Am., 65: 581-626(1975).

[37] McCann, M.W. Jr. and Shah, H.C., Determining strong-motion duration of earthquakes. Bull. Seism. Soc. Am., 69: 1253-1265 (1979).

[38] Vanmarcke, E.H., Structural response to earthquakes. in: C.L. Lomritz and E. Rosenblueth, (ed.). Seismic Risk and Engineering Decisions, Chap. 8, Elsevier. New York (1976). 
تطبيـقات لطرق تحليل الحهـطر الزلزالي وبحاكاة الزلازل في المنطقــة الغربيـة بالمملكة العربية السعودية السرالية

\author{
سمير عبد الله عاشور و حمدي حمدان عبد الرحمن

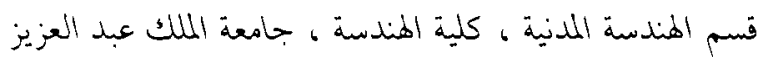

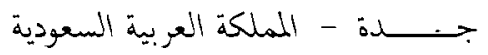

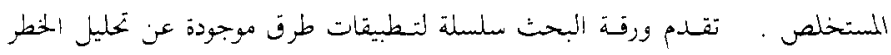

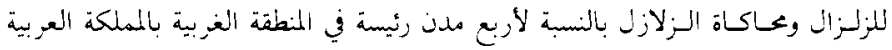

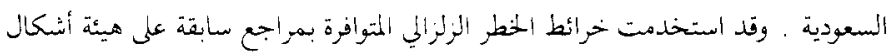

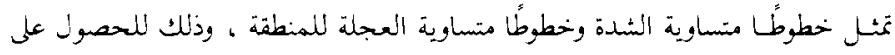

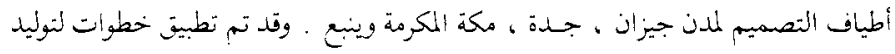

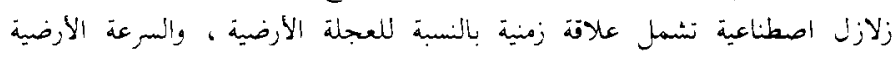
والمسافة . زلت.

ويعتقد أن هذه الزلازل الاصطناعية تعكس بطر بقة معقولة الطبيعة الجيولوجية والزلزالية

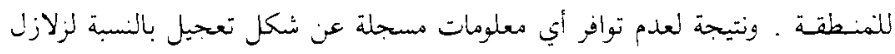

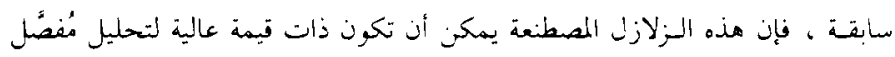

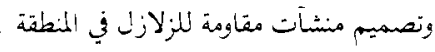

